\title{
A Free from Drugs Narkoba Module by Improving Abstinence Self Efficacy Through Group Cognitive-Behavioral Intervention
}

\author{
1Irmawati, Josetta M.R. Tuapattinaja ${ }^{2}$ \\ ${ }^{1}$ Department of Social Psychology \\ 2Department of Clinical Psychology \\ University of Sumatera Utara \\ Medan, Indonesia \\ Email: Irmawati_usu@yahoo.com
}

\begin{abstract}
Drug abuse in Indonesia has become a serious national threat and has been declared war on drugs by the President of Republic Indonesia, Joko Widodo while attending a day Narkotika in 2016. The increasing number of rehabilitation centers and drug users who underwent rehabilitation programs does not completely free them from the occurrence of relapse when returning to the society. Therefore, an intervention is needed to increase the confidence of drug users do not consume drugs anymore. The purpose of this research is to create a free from drugs Narkobamodule by improving Abstinence Self Efficacy through Group Cognitive Behavioral intervention using coping skill and cognitive restructuring techniques. The method in this research used experimentally with pretest-posttest control group design with 32 participants divided into 4 groups. Group 1 was given with coping skill technique, group 2 were given with cognitive restructuring technique, group 3 were given with the combination of the two techniques (coping skill and cognitive restructuring), and group 4 did not get any treatment. The effectiveness of intervention seen by the increasing score on Brief Situational Confidence Questionnaire examined with parametric statistics technique. The result of this research showed that the combination of coping skill technique and a cognitive restructuring that was given to the participants work more effectively to improve abstinence self-efficacy than the techniques given separately.
\end{abstract}

Keywords-Abstinence self-efficacy; Copig skill; Cognitive restructuring; Group cognitive behavioral

\section{INTRODUCTION}

Drug abuse in Indonesia has become a national threat that needs to be considered carefully. Many ways have been done to overcome this problem of prevention of drugs, preventively or repressively. Sarafino (2011) explains that the process of recovery of the drug addicts to be able to return to the activity in the environment is not an easy thing and not a short process in order to really be free from drugs. The addicts are susceptible to experience relapse which is the re-use of drugs and this condition is very highly likely to occur in the first week until the first month after quitting the drug use. Minervini(2011) states that the challenges and obstacles that confronting addicts toward recovery are so tough, they have to struggle against the suggestion that continues in their lives and lead them to experience a relapse. Leshner (in National Institute on Drug Abuse, 2009) described high-risk situations that may lead to psychological distress, family problems, illness associated with medical problems, social relations, even smells related to medicines, drugs can be the trigger for the occurrence of relapse.
Marlat and Gordon (in Handershot, 2011) stated that the main factor that causes a relapse is a factor of belief in the ability that he has. Witkiewitz\&Marlatt (in Sarafino, 2006) also explained that one that can cause a relapsing addict is a belief in his low ability. An individual's belief in his ability to resist and remain unconventional so that no experiencing relapse is called abstinence self-efficacy (Majer, 2004). Abstinence self-efficacy determines how an individual feels, think and encourage them to not consume drugs anymore. Individuals who have confidence in their abilities will view the highrisk situation as a challenge that must be mastered or faced and not as a threat to be avoided. According to Marlat and Gordon (in Handershot, 2011) an individual can increase his confidence to refuse using drugs by applying proper coping techniques. Previously, Chiang (2006) stated that addicts need to do cognitive restructuring by restructuring their irrational thoughts about the benefits of drug use such as drugs can help solve problems, increase selfesteem, without drugs it will reduce the physical ability to work and be able to overcome various problems daily. 
Improved coping and cognitive restructuring skills are a technique incorporated in Cognitive Behavioral (CB) interventions. The most popular application of this intervention is the coping skill technique. Julian (2007) explained that most practitioners who perform Cognitive Behavioral interventions use coping skills techniques because these techniques help individuals to recognize high-risk situations and apply appropriate coping techniques to deal with. On the other hand, Bernand (2012) asserted that an addict not only requires an increase in coping skills but it is necessary to establish a rational cognitive status.

Based on this description, the researcher considers that it is necessary to conduct CB interventions by using coping skills and cognitive restructuring techniques in an effort to help addicts increase their confidence in their ability to resist drug use. This intervention will be given in groups by involving a number of addicts to be more efficient in terms of time, cost, and energy.

In addition, Group Cognitive Behavioral (GCB) can also provide an open space for addicts to interact so that each individual in the group able to express thoughts and feelings freely, mutual attention, mutual understanding, mutual help and mutual trust to solve problems (Bieling, 2006).

Thus, the purpose of this study was to see if Group Cognitive Behavioral interventions by combining skill coping and cognitive restructuring techniques would be more effectively increase the abstinence of self-efficacy compared to be given separately.

\section{METHODS}

This research used experimental with pretest-posttest control group design, with abstinence self-efficacy as dependent variable while Group Cognitive Behavioral by using cognitive restructuring technique, coping skill technique and the combination of cognitive restructuring technique and coping skill as the independent variable. The study was conducted in two drug rehabilitation centers in Medan, using purposive sampling technique with sample criteria are drug addicts who are in the process of recovery, are not using drugs or drug therapy, have no symptoms of intoxication or withdrawal, and have been treated at least 1 month. Abstinence self-efficacy measured through a Brief Situational Confidence Questionnaire (BSCQ) with validity values obtained from antiimage correlation greater than 0.5 and an alpha reliability value of 0.892 . The technique of data analysis in this research include two part that is assumption test and hypothesis test. Test assumption using Kolmogorov-Smirnov (0.104, $\mathrm{df}=32, \mathrm{p}=0.200)$ and Levene test $(0.057, \mathrm{df}=32$, $\mathrm{p}=0.982$ ), while hypothesis test using two subanalysis that is Independent T-Test for withinsubject and ANOVA Test for between subject.

\section{RESULT AND DISCUSSION}

Based on the Independent T-Test of each group of experimental group 1 (coping skill), experimental group 2 (cognitive restructuring), experimental group 3 (combined coping skill and cognitive restructuring), and group 4 (control group) are as follows:

Table 1

Gain score difference on BSCQ experimental group within control group

\begin{tabular}{|c|c|c|c|c|c|}
\hline No & Kelompok & Mean & SE & $\mathbf{t}$ & $\mathbf{P}$ \\
\hline 1 & $\begin{array}{l}\text { Eksperime } \\
\text { n } 1\end{array}$ & 12,25 & 2,169 & \multirow[t]{2}{*}{5,542} & \multirow[t]{2}{*}{0,000} \\
\hline 2 & Kontrol & 4,75 & 2,169 & & \\
\hline 1 & $\begin{array}{l}\text { Eksperime } \\
\text { n } 2\end{array}$ & 12,25 & 2,259 & \multirow[t]{2}{*}{5,507} & \multirow[t]{2}{*}{0,000} \\
\hline 2 & Kontrol & 4,75 & 1,169 & & \\
\hline 1 & $\begin{array}{l}\text { Eksperime } \\
\text { n } 3\end{array}$ & 23,27 & 2,777 & \multirow[t]{2}{*}{7,981} & \multirow[t]{2}{*}{0,000} \\
\hline 2 & Kontrol & 4,75 & 2,169 & & \\
\hline
\end{tabular}

Table 1 above indicates that there is a significant difference in abstinence self efficacy between experimental group 1 that procure the coping skill intervention (Mean $=12,25 \mathrm{SE}=$ $2,169)$ with the control group (Mean $=4.75 \mathrm{SE}=$ $2,169)$ with the value of $t(14)=5.542$ with significance $p=0,000, r=0.82$. The scores indicated that the group receiving coping skill intervention had higher abstinence self-efficacy than the control group, the coping skill intervention had an $82 \%$ effect on the increase in abstinence self-efficacy. There was also a significant difference in the abstinence of self efficacy between experimental group 2 which received cognitive restructuring intervention (Mean $=12.5 \mathrm{SE}=2,259)$ with control group $($ Mean $=4.75 \mathrm{SE}=2,169)$ with $\mathrm{t}$ value $(14)=$ 5,507 with significance $p=0,000, r=0.82$. This score indicates that the group receiving cognitive restructuring interventions had higher abstinence self-efficacy than the control group, 
cognitive restructuring interventions had an $82 \%$ effect on the increase in abstinence selfefficacy. While the experimental group 3 which received a combination of coping skill and cognitive restructuring interventions simultaneously showed significant differences in abstinence self-efficacy compared to the control group (Mean $=4.75 \mathrm{SE}=2.169)$ with $\mathrm{t}$ value (14) $=7.981$ with significance $\mathrm{p}=0,000, \mathrm{r}=0.92$.The scores indicated that the group receiving combined coping skill and cognitive restructuring interventions had higher abstinence self-efficacy than the control group, coping skill interventions and cognitive restructuring interventions simultaneously had a 92\% effect on increased abstinence self-efficacy.

Based on the table shows that there are significant differences in Abstinence Self Efficacy between groups given intervention coping skills (Mean $=12.25 \mathrm{SE}=2.169)$, cognitive restructuring (Mean $=12.5 \mathrm{SE}=2,259$ ), combined cognitive coping skills with cognitive restructuring (Mean $=23,37 \mathrm{SE}=2,777$ ) and control group (Mean $=4,75 \mathrm{SE}=2,169)$, with value $F(31)=24,287$ with significance $p=0,000$, $r=0.84$.

Test through Post-Hoc Multiple Comparison (Bonferroni Test) obtained differences in the increase of abstinence selfefficacy between groups presented in the following table:

\begin{tabular}{|l|l|l|l|l|}
\hline & \multicolumn{4}{|c|}{ Comparison } \\
\cline { 2 - 5 } Group & $\begin{array}{l}\text { Copi } \\
\text { ng } \\
\text { skill }\end{array}$ & $\begin{array}{l}\text { Cognitiv } \\
\text { e } \\
\text { restruct } \\
\text { uring }\end{array}$ & $\begin{array}{l}\text { Coping } \\
\text { skill + } \\
\text { Cognitiv } \\
\text { e } \\
\text { restruct } \\
\text { uring }\end{array}$ & $\begin{array}{l}\text { Contr } \\
\text { ol }\end{array}$ \\
\hline $\begin{array}{l}\text { Coping } \\
\text { skill }\end{array}$ & - & $\mathrm{p}=0,350$ & $\mathrm{p}=0,000$ & $\begin{array}{l}\mathrm{p}= \\
0,000\end{array}$ \\
\hline $\begin{array}{l}\text { Cognitiv } \\
\text { e } \\
\text { restructu } \\
\text { ring }\end{array}$ & $\begin{array}{l}\mathrm{p}= \\
0,350\end{array}$ & - & $\mathrm{p}=0,000$ & $\begin{array}{l}\mathrm{p}= \\
0,000\end{array}$ \\
\hline $\begin{array}{l}\text { Coping } \\
\text { skill + } \\
\text { Cognitiv } \\
\text { e } \\
\text { restructu } \\
\text { ring }\end{array}$ & $\begin{array}{l}\mathrm{p}= \\
0,000\end{array}$ & $\mathrm{p}=0,000$ & - & $\mathrm{p}=$ \\
\hline Control & $\begin{array}{l}\mathrm{p}= \\
0,000\end{array}$ & $\mathrm{p}=0,000$ & $\mathrm{p}=0,000$ & - \\
\hline
\end{tabular}

Table 2

Comparison of increased inter-group efficacy of selfefficacy abstinence
Table 2 shows that there is no difference in the increase in abstinence selfefficacy between groups receiving cognitive restructuring interventions $($ mean $=17.6)$ with those receiving coping skill (mean $=15,8)$ with $p$ $=0.35$. Secondly, there is a difference of abstinence self-efficacy increase between cognitive restructuring group (mean $=15,8$ ) with cognitive restructuring combined group and mean coping skill (mean $=25,8)$ with $p=0,000$. Thirdly, there was a difference in the increase in abstinence of self-efficacy between the groups receiving the coping skill intervention (mean $=$ 17.6) with the cognitive restructuring combined group and the coping skill ( mean $=25.8$ ) with $\mathrm{p}=$ 0,000 . Fourth, there is a difference in the increase in abstinence of self-efficacy between the groups receiving combined coping skills and cognitive restructuring with the control group. It can be concluded that combined coping skills and cognitive restructuring combined will provide a higher Abstinence Self Efficacy improvement compared to separate coping skills and cognitive restructuring.

The results showed that the Cognitive Behavioral Group has an important role in helping drug addicts to be able to resist drug use in the face of situations that are at risk of triggering drug use. This can be explained by using Bandura's theory (in Schutz, 2005) in selfefficacy theory. Self-efficacy is the main basis that directs the emergence of a behavior that is influenced by the aspects of a person (P), behavior (B) and environment (E). By cognitive restructuring the content of a person's mind (P) that drugs are not a way to solve a problem it can help the person to interpret more rationally to the environment / high-risk situation (E) so he will decide to use the right coping skills not to using drugs (B) which will result in high selfefficacy to reject the use of drugs when dealing with high-risk situation.

Norcross \&Goldried (in Keshi, 2013) with reference to Bandura's theory explains that CB is an appropriate intervention to improve selfefficacy because CB is a form of intervention that serves to change the content of thoughts and behaviors so that with the changing contents of these thoughts and behaviors it can also improve self-efficacy. The self-efficacy of a person will increase as he transforms his thoughts into rational and gains an understanding of coping skills techniques so that it can be concluded that both coping skill and cognitive restructuring techniques have the same effect to increase abstinence self-efficacy. Bernard P. Rangé1 and 
Ana Carolina Robbe Mathias (2012) explained that one technique to help improve the ability of addicts not to use drugs is to identify the irrational mind and restructure.

This will make the addict increasingly able to interpret the trigger situation in rational ways so as to weaken the desire to re-use drugs.

Previously, Spiegler (2003) stated that cognitive can be modified in two ways that are behavioral and cognitive. Cognition is altered directly by changing maladaptive thoughts and can also indirectly change their apparent behavior. The technique used in this research is cognitive restructuring technique that aims to change irrational mind to be rational. While coping skill aims to sharpen the skills of individuals to be able to act appropriately when dealing with the high-risk situation. Furthermore, Annis, Sklar\& Moser (in Hagman, 2004) further explained that the ability to cope skills has an important role in improving the abstinence of self-efficacy that can make individuals more confident in their ability to face/cope in a high-risk situation. Marlatt\& Gordon (in Hagman, 2004) also provides a similar explanation, he described that abstinence self-efficacy is a factor that mediates the ability to cope skills with relapse. The more he understands the effective coping techniques he is increasingly convinced of his ability to perform copying of high-risk situations to remain in a state of abstinence.Jafari (2010) then explained that individuals who have learned coping skill techniques and understand them will feel more capable and have a "sense of control" that has an impact on increasing abstinence self-efficacy so as to be able to remain "clean" without the use of drugs when dealing with the high-risk situation. Milkman (2007) explained that there is a strong relationship between the assessment of the environment with self-efficacy. Assessment is a cognitive process to assess the situation or experience. Clark (in Milkman, 2007) explained that this cognitive assessment can be disturbed to become irrational, by identifying these irrational thoughts and replacing them rationally can help individuals become more confident in situations or unpleasant experiences. An individual's appraisal process will be what will happen and what results he will get is important to understand how likely he will behave. An individual who has been able to think rationally will also be able to provide a rational assessment of its ability which further affects behavior. An individual who has realized that taking drugs is not the way to solve the problem, so he will choose not to use drugs in solving the problem. In addition, an individual who already has a rational mind then he will have high expectations of his success to being able to remain abstinence and further increasingly able to manage his thoughts in the face of such risky situations. Bandura in theory about the process of the formation of self-efficacy also explains that the cognitive process has an important role in the formation of self-efficacy. The rational content of the mind will increasingly enable the individual to be able to set realistic goals in accordance with the rational content of the mind so that when he realizes that drugs can damage him he is increasingly able to establish the kind of behavior that aims to control himself not to use drugs.

As explained earlier that in CB, not only use the technique of coping skill but also cognitive restructuring technique that aims to change the irrational mind to be rational, especially in this research is associated with the use of substances. Krista \&Fritson (in Keshi, 2013) have conducted experiments using cognitive structuring techniques. His research proves that cognitive restructuring can improve self-efficacy.

This research also proves that a combination of coping skills and restructuring techniques can be more effective to increase abstinence self-efficacy than the application of the technique separately. When re-examined based on the theory of Bandura that describes the person, behavior, and environment, it is increasingly clear that the combination of these two techniques not only "fix" aspects of $\mathrm{P}$ but also B to face high-risk situation (E). Subjects in this study are a collection of individuals who have problems in terms of irrational thoughts (P) and ability coping skills (B) so that the subject needs to be addressed in both aspects. With the intervention of coping skills, the subject becomes know and acquires new skills to be able to face the high-risk situation, besides being fixed behaviorally, the subject is also fixed in the $\mathrm{P}$ aspect by "fixing" his irrational thoughts by replacing it with a rational mind. This condition that makes increasing abstinence of self-efficacy more than by fixing aspects of person or behavior only. This theory is in line with Rangel's (2012) explanation that addicts need not only intervene coping skills but also need to have a rational mind in the face of high-risk situations, with the ability of effective coping skills and rational thoughts, the subject is more confident in his ability to can face a high-risk situation in 
order to remain in a state of abstinence. Based on the above explanation, researchers believe that the provision of interventions with coping skills and cognitive restructuring techniques simultaneously will increase the abstinence selfefficacy of the addicts to avoid relapse. The implementation of this intervention will then be packaged in modules that can be used by rehabilitation center managers and Psychology practitioners working in the field of drug prevention.

\section{CONCLUSION AND FINDINGS}

Cognitive Behavioral Group Intervention is effective for increasing abstinence self-efficacy in addicts who are in rehabilitation. In more detail, the result shows that both coping skill, cognitive restructuring, and combined techniques can both increase the abstinence of self-efficacy of addicts when dealing high-risk situations. However, the provision of coping skill and cognitive restructuring techniques simultaneously more effective than if given separately. This discovery provides a greater opportunity for drug addicts to be able to avoid relapse.

Based on the conclusions, Psychological Practitioners and Drug Rehabilitation Center Managers can use abstinence self-efficacy as a benchmark for success in helping drug users avoid relapse. To obtain more effective results it is necessary to apply coping skill and cognitive restructuring techniques simultaneously. In addition, to maintain the condition of abstinence in the addicts can then conduct further research by looking at the relationship between abstinence self-efficacy with abstinence behavior.

\section{ACKNOWLEDGEMENT}

Thanks to YustianSinaga, M.Psi, Psikolog has inspired the importance of research related to abstinence self-efficacy in drug users. We also thank the participants (drug users) for allowing this research to proceed as expected.

\section{BIBLIOGRAPHY}

[1] APA, 2004. Diagnostic and Statistical Manual of Mental Disorder 4th Edition Text Revision. Donnelly \& son company: USA

[2] BNN. (2007). Data penyalahgunaan Markova. WWW.BNN.go.id
[3] Bieling Peter J. 2006. Cognitive Behavioral Therapy in Groups. The Guilford Press: London

[4] Chiang, Chen-Heng. 2006. The relationships among personality traits, irrational beliefs, craving and relapse intention of male amphetamine Abusers. Taiwan University of Technology: Taiwan

[5] Field, Andy. 2005. Discovering Statistics Using SPSS, 3rd Ed. London: SAGE Publication

[6] Fraenkel, Jack R dan Norman E. Wallen. 2006. How to Design and Evaluate Research in Education. New York: McGraw-Hill Inc

[7] Hagman, Brett T. 2004. Coping And SelfEfficacy As Predictors of Substance Use During The First Few Critical Months Following Substance Abuse Treatment Completion.

[8] Hendershot, Christian S. 2011. Relapse prevention for addictive behaviors. BioMed Central Ltd: Canada

[9] Hankins, J Hayden. 2008. Increase Selfefficacy in the Context of Addiction Behaviours. Journal of Health Psychology SAGE Publications: King's College London, UK

[10] Ilgen, Mark. 2005. Abstinence Self-Efficacy and Abstinence 1 Year After Substance UseDisorder Treatment. Journal of Consulting and Clinical Psychology In the public domain: Stanford University School of Medicine

[11] Jafari, Mostafa. 2012. Comparing the effectiveness of Cognitive Behavioral Therapy and Stages of Change Model on Improving Abstinence Self-Efficacy in Iranian Substance Dependent Adolescents. Department of Psychology, Shahid Beheshti University: Tehran, Iran.

[12] Keshi, Ali Khaneh. The effectiveness of cognitive behavior therapy on self-efficacy Among high school students. Department of Psychology, University of Mysore: INDIA.

[13] Leshner, Alan I. 2009. Principles of drug addiction.National Institute on Drug Abuse: NIH Publication

[14] Martin \& Pear, 2007, Behavior Modification $8^{\text {th }}$ ed. Pearson Prentice Hall: USA

[15] Majer. John M. 2004. Optimism, Abstinence Self-Efficacy, and Self-Mastery A Comparative Analysis of Cognitive Resources. DePaul UniversityAssessment, Volume 11, No. 1 Sage Publications: UK 
[16] Minervini, Iacopo. 2011. Desire and Coping Self-Efficacy as Craving Measures in Addiction: The Self-Efficacy and Desire Scale (SAD. The Open Behavioral Science Journal: Italy

[17] Nolen, Susan, 2007. Abnormal Psychology 4th Edition. McGraw-Hill Companies: New York

[18] Rangé1 Bernard P. 2012. Cognitive-Behavior Therapy for Substance Abuse. Federal University at Rio de Janeiro: Brazil
[19] Sarafino, Edward P. 2006. Health Psychology Biopsychosocial Interaction. New York: JohnWiley \& Sons

[20] Schultz, D. P (2005). Theories of Personality. $8^{\text {th }}$ ed. Australia: Thomson Wadswarth

[21]Schultz, D. P (2011). Theories of Personality.9th ed. Australia: Thomson Wadswarth

[22] Spiegler, Michael D. 2003. Contemporary Behavior Therapy. Wadsworth: USA 